\title{
CHANGES IN LIGHT SCATTER AND WIDTH MEASUREMENTS FROM THE HUMAN LENS CORTEX WITH AGE
}

\author{
GEORGE T. H. SMITH, ROSALIND C. SMITH, NICHOLAS A. P. BROWN, ANTHONY J. BRON \\ MARTIN L. HARRIS \\ Oxford
}

\begin{abstract}
SUMMARY
Light scatter and width measurements of the anterior cortical layers of the human lens were made in $\mathbf{5 0}$ eyes of 50 subjects using computerised linear scanning densitometry of Scheimpflug images. It was demonstrated that the amount of light scatter increased with age in all of the three major zones and that zone $\mathrm{C} 3$ showed the most marked increase. Most lens growth occurs in zone C2 with $\mathrm{C3}$ showing little increase in width once it has become established. Zone $\mathrm{C} 1$ showed a tendency to decrease in width with age. In addition it was shown that the C3 zone, which is not present at birth and during early childhood, appears as a distinct layer during the second decade of life. Its scattering properties continue to increase throughout life, exceeding all other zones after approximately 30 years of age, in the absence of cataract. Possible explanations for the lens zone pattern are discussed.
\end{abstract}

The human lens grows throughout life at a rate of approximately $0.03 \mathrm{~mm}$ per year. ${ }^{1}$ Lens growth results from surface accretion (the addition of new lens fibres) but it is believed that this is offset by a process known as compaction (the compression of existing fibres). ${ }^{1.2}$ It has been calculated by observing the rate at which glaucoma flecks and traumatic cataracts sink into the lens that the rate of compaction is approximately half the rate of accretion. ${ }^{1}$ By the time early adulthood is reached several distinct concentric layers can be distinguished by their different light scattering properties, using biomicroscopy. This layered structure can best be appreciated at about age 40 years. ${ }^{3,4}$ Five cortical layers can normally be identified; $\mathrm{C} 1$ alpha, $\mathrm{C} 1$ beta, $\mathrm{C} 2, \mathrm{C} 3$ and $\mathrm{C} 4$ (Fig. 1) $\mathrm{C} 1$ beta and $\mathrm{C} 3$ are zones of high light scatter whereas $\mathrm{C} 1$ alpha, $\mathrm{C} 2$ and $\mathrm{C} 4$ are zones of low light scatter. $\mathrm{C} 1$ beta has been shown to

The Clinical Cataract Research Unit, Nuffield Laboratory of Ophthalmology, Walton Street, Oxford OX2 6AW.

Correspondence to: George T. H. Smith FRCS, FCOpth. The University of Melbourne Department of Ophthalmology, The Royal Victorian Eye and Ear Hospital, 32 Gisborne Street, East Melbourne, Victoria 3002, Australia. decrease in width and brightness with age. ${ }^{4.5}$ Zonc $\mathrm{C} 1$ lies within the most metabolically active part of the human lens cortex and has been shown to be affected by conditions that result in decreased lens growth. ${ }^{6.7}$

Despite the attention that has been paid to zone $\mathrm{C} 1$, there appears to have been few investigations into the other cortical layers, also termed the 'zones of discontinuity'. ${ }^{4}$ The aim of this study was to examine the development and change in light scattering properties, with age, of the anterior cortical zones.

\section{MATERIAL AND METHODS}

Fifty normal eyes of 50 healthy subjects were examined using computerised analysis of Scheimpflug images. The subjects were recruited from two main sources: (1) hospital staff and (2) friends and relatives of subjects attending the unit for other trials. Their ages ranged from four to 81

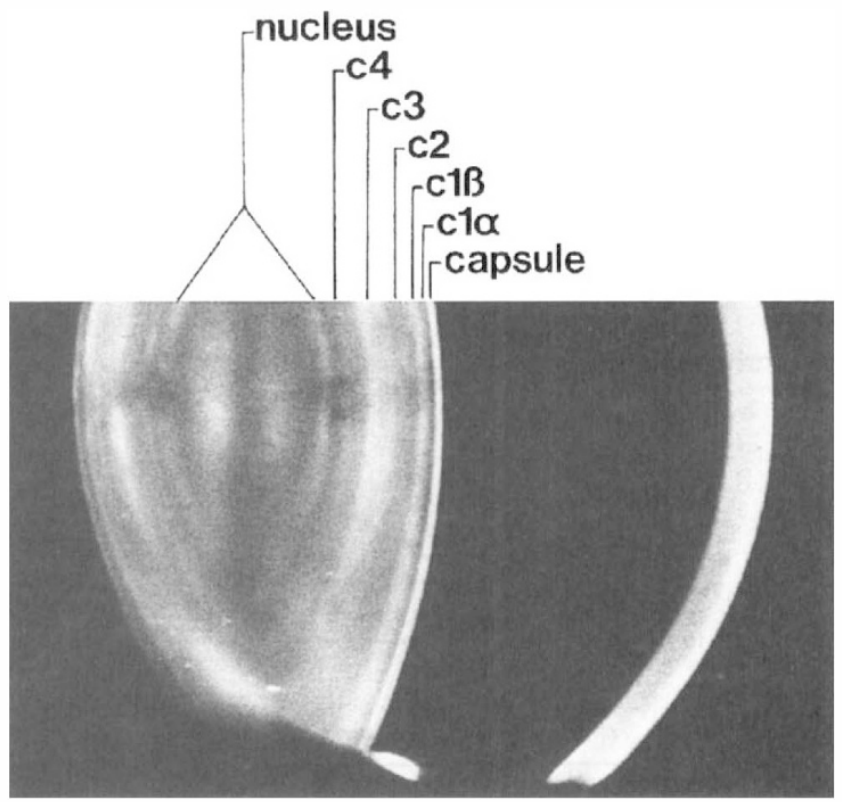

Fig. 1. Scheimpflug photograph of a 45 year old human lens. It is possible to differentiate 5 cortical zones. 


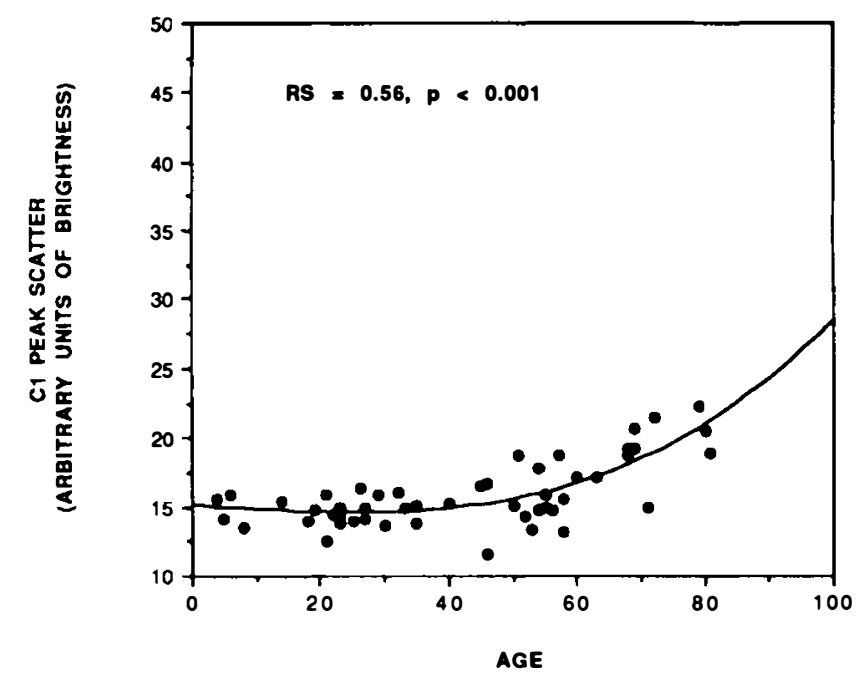

Fig 2a.

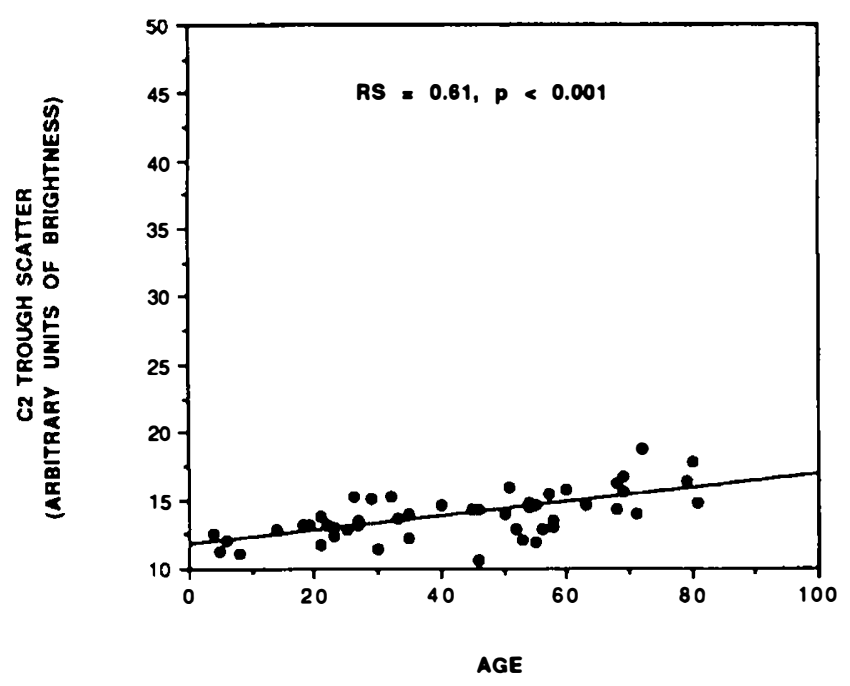

Fig 2b.

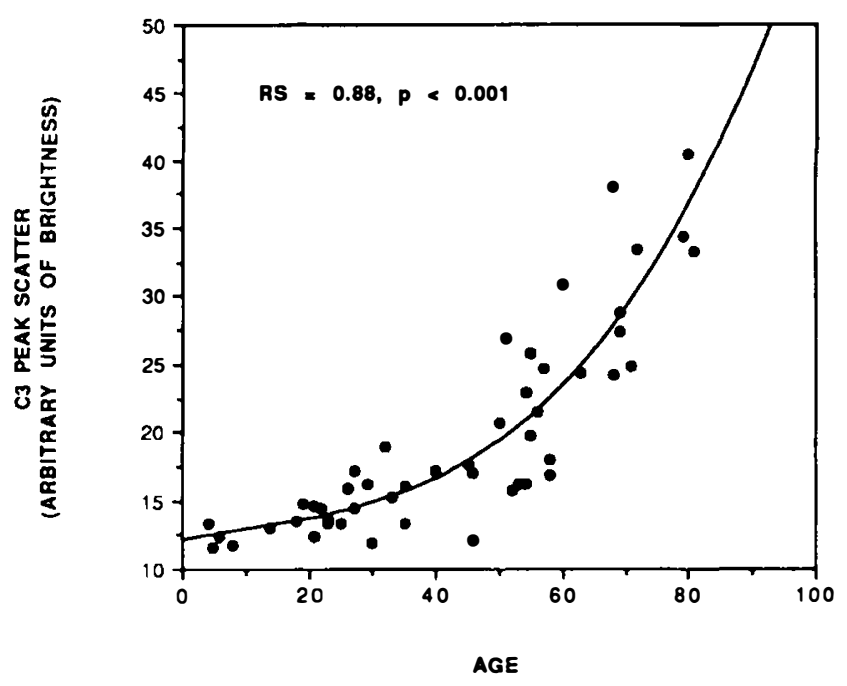

Fig 2c.

Fig. 2a, b and c. The amount of light scatter increases with age from each of the three main cortical zones. C3 show's the most marked increase.

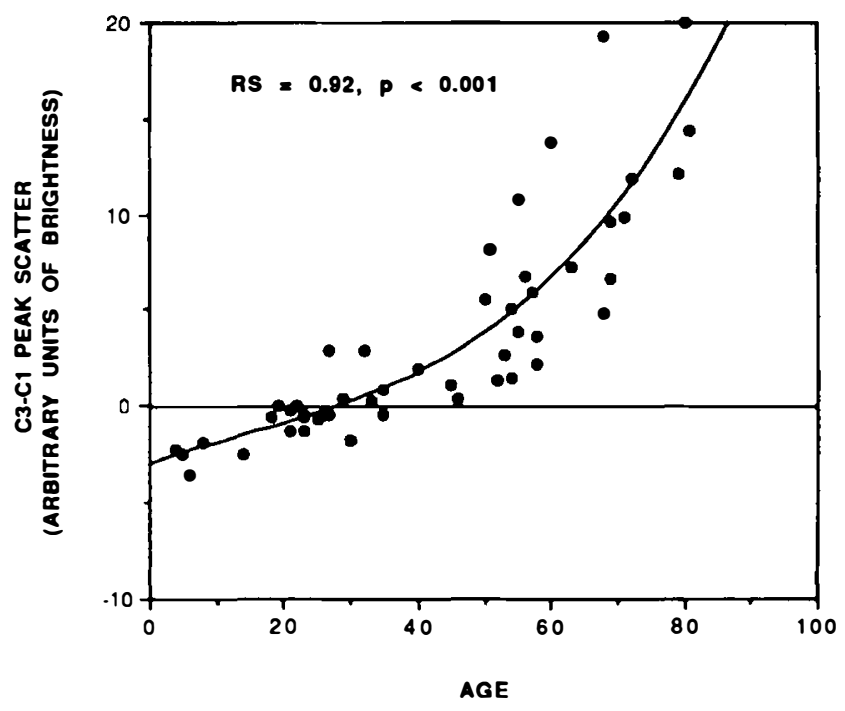

Fig. 3. The scatter from $C 3$ continues to increase throughout life. It exceeds the light scatter from Cl, the other bright cortical zone, after the age of about 30 years.

years. Subjects that had a history of prolonged administration of eye drops or of significant eye disease or trauma were excluded.

After full pupil dilation with tropicamide $1 \%$ and phenylephrine $10 \%$, the subjects' lenses were graded using the Oxford Clinical Cataract Classification and Grading System. ${ }^{3}$ Subjects with any cortical or posterior subcapsular lens opacities and any with greater than grade 2 nuclear brunescence or nuclear white scatter were excluded.

Images were taken on an Oxford charge coupled device Scheimpflug camera* and fed directly into the frame store of an Epson 80286 desktop computer. The Scheimpflug camera is of the same basic design as that described by Brown which controls alignment and fixation of the eye. The image of the right lens was chosen for analysis in all cases except three where the left image was the only one available.

After storage on an optical disc, the images were analysed by computerised linear scanning densitometry using The Oxford Modular Cataract Image Analysis System as described by Sparrow et al. ${ }^{9.10}$ This technique compensates for linear distortion inherent in the Scheimpflug method and calculates light scatter from the lens relative to the intensity of light passing through neutral density filters within the camera. A sagittal strip of image measuring five pixels on either side of a central line is used for analysis.

Both the maximum scatter and the width of zones $\mathrm{Cl}$, $\mathrm{C} 2$ and $\mathrm{C} 3$ were measured. The distance from the capsule to the $\mathrm{C} 3$ peak, the distance from the $\mathrm{C} 3$ peak to the centre of the nucleus, the total lens width and the amount of scatter from the centre of the nucleus were also measured. The $\mathrm{Cl}$ width measurement represented the sum of the capsule, $\mathrm{Cl}$ alpha and $\mathrm{Cl}$ beta since these could not be resolved separately by the system.

In five cases, under the age of 20 years, where the $\mathrm{C} 3$ peak was poorly formed, the scatter was estimated by *Supplied by Marcher Enterprises Ltd, 6 Twyford Road, Rotherwas Industrial Estate, Hereford HR2 6JR, England. 


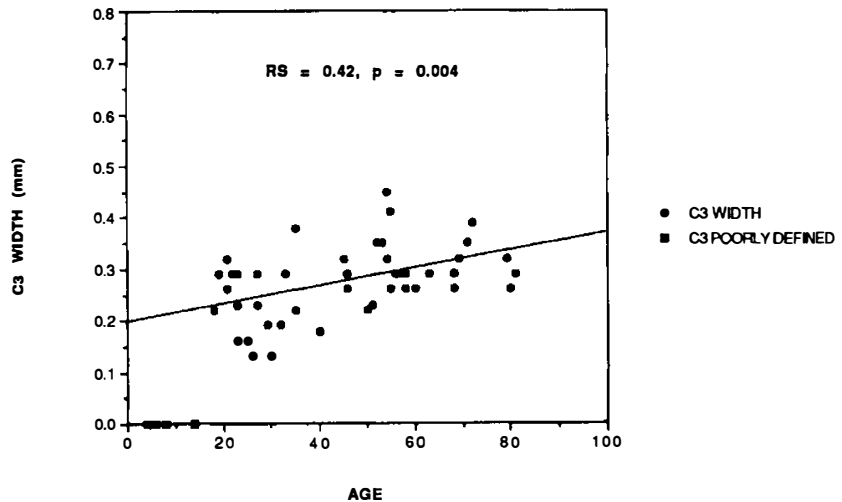

Fig. 4. The C3 zone shows only a small increase in width, with age, once it has become established.

positioning the cursor at the position where it was expected to develop. In such cases it was not possible to measure the width of $\mathrm{C} 3$. It was found that zone $\mathrm{C} 4$ was very difficult to distinguish from the anterior nuclear layers and could not be measured accurately.

Spearman's rank correlation coefficients (RS) and p values were calculated using the Oxstat statistical package on an IBM compatible microcomputer.

\section{RESULTS}

It was shown that there was a positive correlation between the amount of scatter from each of the three anterior cortical zones and the age of the subjects. $(\mathrm{C} 1: \mathrm{RS}=0.56$, $\mathrm{p}<0.001, \mathrm{C} 2: \mathrm{RS}=0.61, \mathrm{p}<0.001, \mathrm{C} 3: \mathrm{RS}=0.88$, p $<0.001$ (Fig. 2 a-c)).

$\mathrm{C} 3$ showed the greatest increase and $\mathrm{C} 1$ also showed a marked increase, especially after the age of about 45 years, with the points in both plots fitting a third order polynomial equation. In subjects under the age of 20 years, C3 was poorly developed, or not present. However, the zone appears during the second decade and rapidly increases in width and scatter until it becomes the zone of the lens which scatters the most light by about age 30 years (Fig. 3). The zone then continues to increase in scatter but

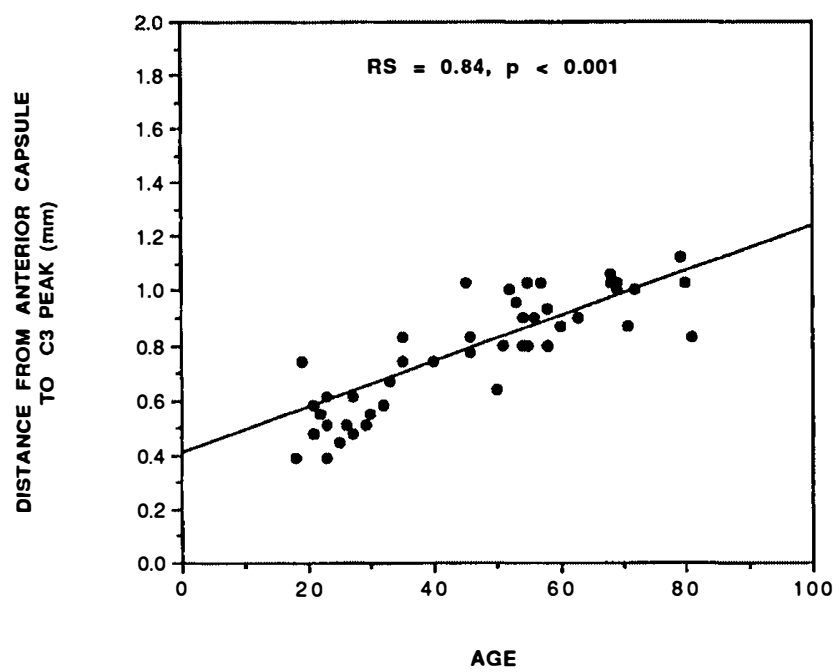

Fig. 5. The C3 peak moves further from the lens capsule with age.

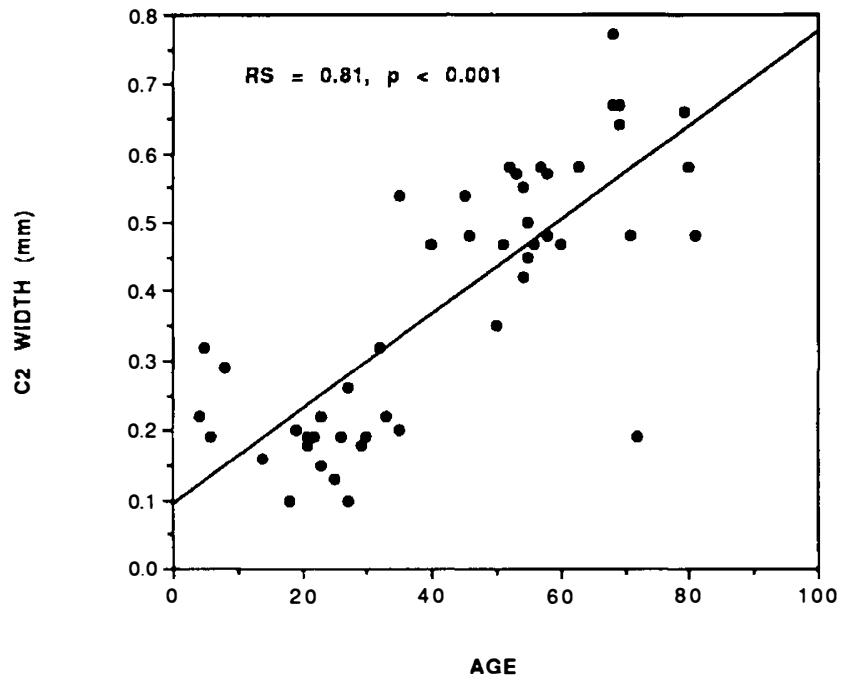

Fig. 6. The C2 zone shows a marked increase in width with age.

only slightly in width ( $R S=0.42, p=0.004$, Fig. 4$)$. It was shown that the distance of the $\mathrm{C} 3$ peak from the lens capsule increases with age $(\mathrm{RS}=0.84, \mathrm{p}<0.001$, Fig. 5$)$ and that there was a marked increase in the width of zone $\mathrm{C} 2$, (RS $=0.81, \mathrm{p}<0.001$, Fig. 6).

The position of the $\mathrm{C} 3$ peak relative to the centre of the nucleus remains almost constant throughout life $(\mathrm{RS}=$ $0.10, \mathrm{p}=0.498$, Fig. 7).

The width of zone $\mathrm{C} 1$, which here is a combined measurement of the capsule, $\mathrm{C} 1$ alpha and $\mathrm{C} 1$ beta, showed a tendency to decrease with age $(\mathrm{RS}=-0.43$, $\mathrm{p}=0.002$, Fig. 8). This study confirmed that the total lens width increases with age $e^{4,5,11,12,13}$ and also that the scatter from the centre of the nucleus increases ${ }^{4,5,9,14}(\mathrm{RS}=0.84$, $\mathrm{p}<0.001$ and $\mathrm{RS}=0.81, \mathrm{p}<0.001)$.

\section{DISCUSSION}

Goldmann and Huggert, as long as 50 years ago, quantitatively studied visible changes in the lens with age. Using optical methods, they found that the most characteristic

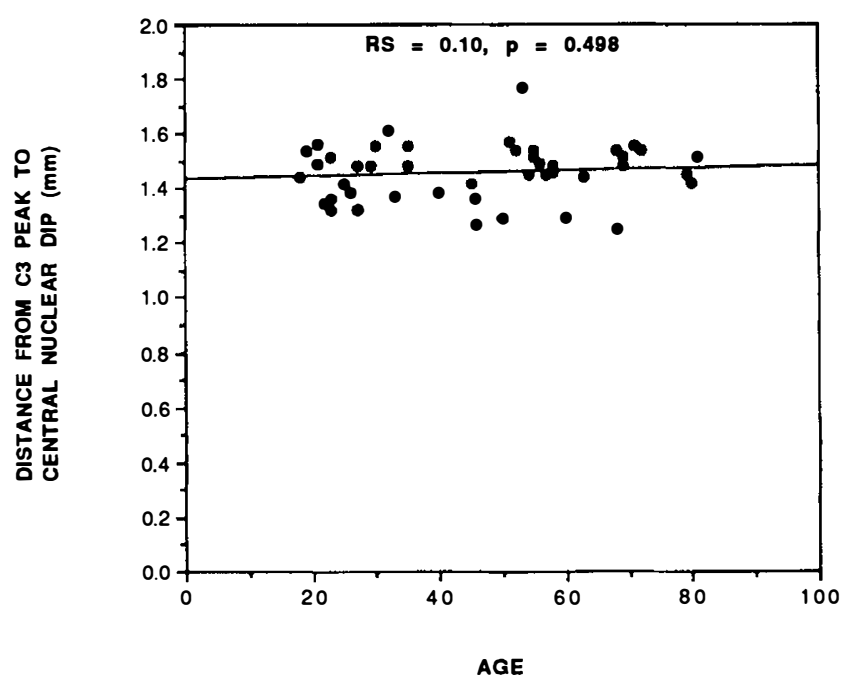

Fig. 7. The $C 3$ peak remains at a constant distance from the centre of the lens. 


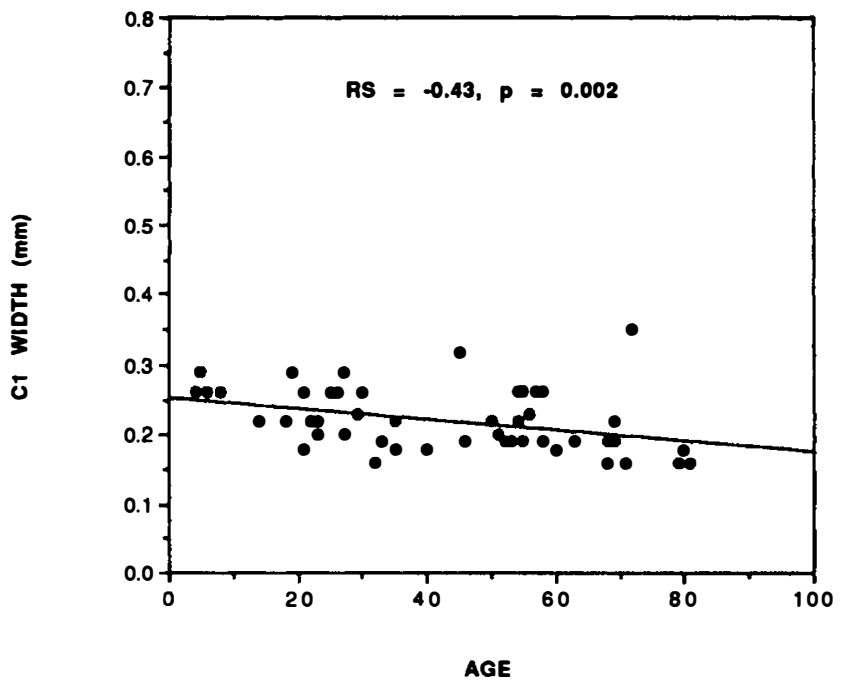

Fig. 8: The Cl zone shows a tendency to decrease in width with age.

sign of ageing was a continuous thickening of lens cortices that occurred together with an increase in the number of discontinuity zones in the cortex. ${ }^{15,16,17}$

Densitometry of Scheimpflug images is a well recognised technique for measuring the amount of light scatter from objects in the anterior eye segment. ${ }^{9,10,11,14}$ It has also been shown to be an accurate method for making biometric measurements in the human lens, being compared favourably to other optical and ultrasonic methods of biometric assessment by Koretz et al. ${ }^{18,19}$

Strictly speaking, the densitometric analysis of Scheimpflug photographs measures both real and apparent (believed to be specularly reflected) light scatter, as has been pointed out by Weale. ${ }^{20,21}$ The zones of discontinuity, however, have traditionally been observed at the slit lamp without the use of polarising filters so that the clinician describes the appearance of the zones as seen by both real and apparent light scatter. It was felt that in order to prevent confusion with nomenclature and the introduction of complex theoretical discussions as to what actually constitutes 'scatter' that the term 'light scatter' should be retained, in this work, to encompass both real and apparent scatter.

The zones of discontinuity of the human lens result from the differing light scattering properties of the fibres in each zone. Huggert ${ }^{22}$ believed that the light scattering properties of individual lens zones result from variations in refractive index between the zones, while within a zone the refractive index is more homogeneous (iso-indicial).

Most of the light scatter is thought to arise from fibre cell membranes which have a higher refractive index than the surrounding cytoplasm. ${ }^{23}$ Vinciguerra and Bettelheim showed by laser diffraction that membrane to membrane distances in the bovine lens become progressively smaller from cortex to nucleus. ${ }^{24}$ If this occurs in the human lens it may reflect compaction of fibres as they come to lie further from the surface.

The large particle light scattering theory states that destructive interference is dependent on the degree to which the distances between the scattering surfaces are out of phase with the wavelength of the incident light. ${ }^{25} \mathrm{It}$ seems reasonable to postulate, therefore, that the amount of light scatter from a particular zone is related to the thickness of the fibres that it contains.

Compaction of lens fibres has been shown to occur by observation of cortical opacities in subjects of a wide age range $^{1}$ and by observation of nuclear opacities in young subjects. ${ }^{2}$ As new fibres are added to the surface of $\mathrm{C} 1$ alpha, the deeper fibres undergo a change in their light scattering properties. The superficial cortical fibres represent a shifting population and change their character in terms of light scatter as they sink into the lens with time. ${ }^{1}$ These fibres thus pass through a phase of increased light scatter as they enter $\mathrm{C} 1$ beta, and then of decreased scatter when they are incorporated into $\mathrm{C} 2$. Zone $\mathrm{C} 1$ beta exhibits a relative constancy of thickness as a 'standing wave', ${ }^{26}$ while $\mathrm{C} 2$ expands with time.

In this study only the anterior cortex was assessed, as light scatter from the posterior cortex would be affected by the light scattered from the anterior cortex and the nucleus. As only a central strip of lens was studied, it is possible that the characteristics of the zones examined may be different in the periphery of the lens.

Scatter from each of the three cortical zones examined increases with age and the most marked increase is in zone C3. This is in agreement with the work of Eckerskorn ${ }^{14}$ who also found that the deep anterior cortex showed the highest increase in light scattering with age.

The time of appearance of the cortical zones is of interest. In the first decade there are only two distinct cortical zones, $\mathrm{C} 1$ and $\mathrm{C} 2$. The third cortical zone arises as a region of increased light scattering in an established set of deep cortical fibres. Most of the growth occurs in zone C2, with C3 showing little increase in width once it has become established. Zone $\mathrm{Cl}$ showed a tendency to decrease in width with age. This is in keeping with the work of Niesel ${ }^{4,5}$ who also found that $\mathrm{Cl}$ decreased in width. It is shown here that the distance from the $\mathrm{C} 3$ peak to the lens centre does not change with age. If $\mathrm{C} 3$ represents a fixed population of fibres (unlike C1 $\beta$ ), this implies that lens compaction central to $\mathrm{C} 3$ has ceased by the time of its appearance. Since the process of compaction proceeds into late adult life, the inference is, that compaction after this time occurs in the cortex, perhaps at the level of C3 itself.

Niesel $^{4,5}$ and Brown ${ }^{11}$ have also shown that the nucleus changes little in width with age and that most of the growth occurs in the cortex.

Fisher's data, ${ }^{27.28}$ which shows a progressively decreasing modulus of elasticity for human lens capsules, with age, and an increasing one for the lens substance, and also Van Heyningen's finding ${ }^{29}$ that after the third decade of life, the hydration of the human lens remains virtually constant, may conflict with the concept of compaction.

Other factors which may contribute to the degree of light scatter from the cortex include the molecular state of the crystallins within the fibres ${ }^{30}$ and the level of complexity of the fibre interdigitations. ${ }^{31}$ 
Bours et al.$^{32}$ have shown that the dry weight of the crystallins increases significantly from anterior cortex to nucleus. He also showed that the percentage of water soluble crystallins decreases whereas the percentage of water insoluble crystallins increases from anterior cortex through to the posterior supra nuclear layer. In another study by Satoh, ${ }^{33}$ it was demonstrated that there was an increase in the total amount of protein with age but that the protein concentration did not alter. Bettelheim, however, believes that little scatter occurs from the cytoplasm as the crystallin macromolecules are closely packed with little refractive index change between them..$^{23}$

Travers $^{31}$ has shown that the nature of the fibre cell interdigitations changes from superficial to deep in the lens of the Cynomolgus monkey. In the most superficial fibres, 'finger like protrusions' are found which give way to 'ball and socket' attachments in the deeper cortex. These in turn change to 'tongue and groove' attachments in the deep cortex and nucleus. Similar structures have been found in human lenses. ${ }^{30.34,35}$

It is our belief that the intra-fibre membrane separation plays an important role in the generation of the zone system in the normal human lens and that the work of Brown ${ }^{1.2}$ strongly supports the theory of compaction. The fibre cell interdigitations and possibly the protein content of the cytoplasm may also play a role.

Key words: Computerised linear scanning densitometry, Human lens, Light scatter, Scheimpflug photograph.

\section{REFERENCES}

1. Brown NAP: Dating the onset of cataract. Trans Ophthalmol Soc UK 1976, 96: 18-23.

2. Brown NAP, Sparrow JM, Bron AJ: Central compaction in the process of lens growth as indicated by lamellar cataract. Br J Ophthalmol 1988, 72: 538-44.

3. Sparrow JM, Bron AJ, Brown NAP, Ayliffe W, Hill AR: The Oxford clinical cataract classification and grading system. Internat Ophthalmol 1986, 9: 207-25.

4. Niesel P: Visible changes of the lens with age. Trans Ophthalmol Soc UK 1982, 102: 327-30.

5. Niesel P, Krauchi H, Bachmann E: Der Abspaltungstreifen in der Spaltlampen photographie der alternden Linse. $V$ Graefes Arch Klin Exp Ophthalmol 1976, 199: 11-20.

6. Brown NAP and Tripathi R: The loss of the anterior subcapsular clear zone of the lens: Prognostic significance in cataract formation. Trans Ophthalmol Soc UK 1974, 94: 29-45.

7. Perkins ES: Lens thickness in early cataract. $\mathrm{Br}$ J Ophthalmol 1988, 72: 348-53.

8. Brown N: An advanced slit-image camera. BrJ Ophthalmol 1972, 56: 624-31.

9. Sparrow JM: The lens in diabetes. D.Phil Thesis. Oxford, 1989: 97-9, 147-8.

10. Sparrow JM, Brown NAP, Shun-Shin GA, Bron AJ: The Oxford modular cataract image analysis system. Eye 1990, 4: $638-48$.

11. Brown NAP: Biometry of the lens of the eye. M.D. Thesis. Cambridge, 1975: 59-60.
12. Smith P: On the growth of the crystalline lens. Trans Ophthalmol Soc UK 1883, 3: 79-99.

13. Jansson F: Measurement of intraocular distances by ultrasound and comparison between optical and ultrasonic determinations of the depth of the anterior chamber. Acta Ophthalmol (Kbh) 1963, 41: 25-61.

14. Eckerskorn U, Kokkas K, Hockwin O, Laser H, Janke M: Physiological changes of lens transparency during ageing: A Scheimpflug Photography Study. Dev Ophthalmol 1989, 17: $72-4$.

15. Goldmann H: Studien uber den Alterskernstreifen der Linse. Arch $f$ Augenh 1937, 110: 405-14.

16. Huggert A: The thickness of the cortex of the crystalline lens at different ages. Acta Ophthalmol 1946, 24: 43-62.

17. Goldmann H: Senile changes of the lens and the vitreous. Am J Ophthalmol 1964, 57: 1-13.

18. Koretz JF, Kaufman PL, Neider MW, Goeckner PA: Accommodation and presbyopia in the human eye-ageing of the anterior segment. Vis Res 1989, 29: 1685-92.

19. Koretz JF, Kaufman PL, Neider MW, Goeckner PA: Accommodation and presbyopia in the human eye. 1: Evaluation of in vivo measurement techniques. Appl Optics 1989, 28: 1097-102.

20. Weale RA: New method for visualising discontinuities in the crystalline lens. Br J Ophthalmol 1986, 70: 925-30.

21. Weale RA: Real light scatter in the human crystalline lens. Graefe's Arch Clin Exp Ophthalmol 1986, 224: 463-6.

22. Huggert A: Are the discontinuity zones of the crystalline lens iso-indicial surfaces? Acta Ophthalmol 1946, 24: 417-21.

23. Bettelheim FA: Physical basis of lens transparency. In Maisel H. Ed. The Ocular Lens Structure, Function and Pathology. New York: Dekker Inc, 1985: 278.

24. Vinciguerra MJ and Bettelheim FA: Packing and orientation of fibre cells. Exp Eye Res 1971, 11: 214-19.

25. Trokel S: The physical basis for transparency of the crystalline lens. Invest Ophthalmol 1962, 1: 493-501.

26. Brown $\mathrm{N}$ and Hungerford $\mathrm{J}$ : The influence of the size of the lens in ocular disease. Trans Opthalmol Soc UK 1982, 102: 359-63.

27. Fisher RF: Elastic constants of the human lens capsule. J Physiol (Lond) 1969, 201: 1-19.

28. Fisher RF: The elastic constants of the human lens. J Physiol (Lond) 1971, 212: 147-80.

29. Van Heyningen R: The human lens 111 . Some observations on the post mortem lens. Exp Eye Res 1972, 13: 155-60.

30. Kuwabara T: The maturation of the lens cell: A morphological study. Exp Eye Res 1975, 20: 427-43.

31. Travers MJ: Structural correlates of shape change in the primate crystalline lens. D.Phil. Thesis. The City University, London. June 1990, 47-51.

32. Bours J, Wegener A, Hoffman D, Fodisch HJ, Hockwin O: Protein profiles of microsections of the fetal and adult human lens during development and ageing. Mechan Ageing Develop 1990, 54: 13-27.

33. Satoh K: Age related changes in the structural proteins of the human lens. Exp Eye Res 1972, 14: 53-7.

34. Dickson DH and Crock GW: Interlocking patterns on primate lens fibres. Invest Ophthalmol 1972, 11: 809-15.

35. Stirling RJ and Griffiths PG: Scanning EM studies of norman human lens fibres and fibres from nuclear cataracts. Eye 1991, 5: 86-92. 